\title{
From the Founder
}

\section{How It All Began}

Frank Eaton

Founder and Publisher, BioTechniques

$\mathrm{T}$ wenty-five years ago the idea burst into my head almost fully formed: I'd launch a new journal intended to unite many of the disparate life sciences by focusing on one increasingly important commonality - laboratory techniques and methods. It would take the novel approach of being both peerreviewed and free of charge. I'd call it ... BioTechniques.

The first issues would be sent to a list of Type I NIH grant recipients that I had compiled - virtually every academic and government bioresearch lab would receive one copy. With an offer of a free subscription for all, the circulation, as they say today, would go viral. After all, who wouldn't want a free, peerreviewed journal with information that was immediately useful.

With a vast circulation and an engaged readership, the journal would become an effective and efficient medium for advertising. Financial success would ensue. Somehow it would all work.

On day two I recognized a few obstacles: I didn't have journal publishing experience; I didn't have a bioscientific background; I didn't know anyone in the scientific community; and I didn't have the financial backing to hire those who did.

I did have, however, some contacts in the lab products industry. I called Phil Norton, who then worked at Seragen. "Can I take you to lunch and get your opinion on an idea I have?" He liked it. "Do you have any contacts in academia?" He did. "Can you help me put together an editorial board?" He would try. Jeff Felton's article on page $\mathbf{5 9 5}$ picks up the details. Many thanks to each of you who helped so much in those formative stages.

Like any bootstrap entrepreneurial venture, the early going was a struggle. It was the days of photo type and paste-up artistsbefore word processing and electronic page makeup. I remember cutting and pasting a dummy mockup of the first issue on my kitchen table. I learned to do web press page impositions, sell ads, type invoices, and even collect overdue bills.

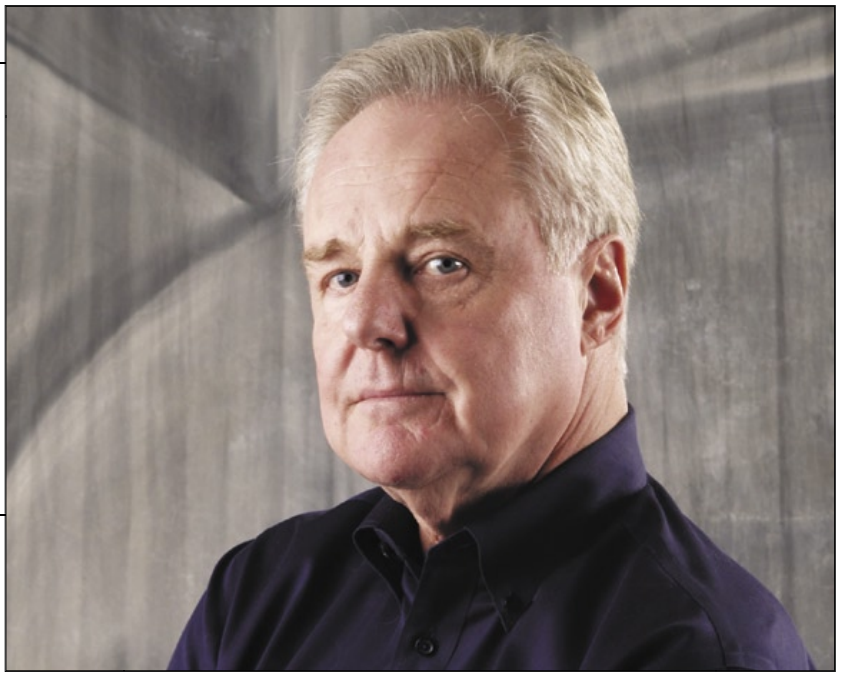

In relatively short order, however, we were able to build an organization of hard-working, loyal, and talented individuals who collectively brought the journal to where it is today.

Much of the credit for the journal's success must also go to the scientific community itself, including the distinguished scientists who have served on the Editorial Board; the authors who have eagerly shared their discoveries and experiences in laboratory technology; and the thousands of scientists who have taken the time to provide thoughtful reviews of submitted papers.

BioTechniques has been witness to many developments in laboratory techniques, the most memorable being, perhaps, PCR. At one point we were accused of "becoming a PCR journal." of course the journal was simply fulfilling its goal of bringing the most important methods information of the day to the laboratory scientist. In this manner, I like to think that the journal has and will continue to play a small but significant role in the overall advancement of biotechnology and the life sciences.

Finally, it is important to recognize that BioTechniques could not exist in its present form without the support of its advertisers. Thanks to all of the companies that have made it possible.

I would love to hear from anybody associated with BioTechniques over the years, including friends, employees, editors, authors, advertisers, competitors, etc. Drop me a line at eaton3482@aol.com. 